\title{
Comparative analysis of clinical presentation of community-acquired pneumonia induced by Chlamydia psittaci and Legionella Diagnosed through Metagenomic Next-Generation Sequencing
}

\section{Shanshan Su}

Wenzhou Medical University First Affiliated Hospital

Jiahao Zeng

Wenzhou Medical University First Affiliated Hospital

Yunlei Li

Wenzhou Medical College Affiliated Yueqing Hospital

Pengcheng Lin

Wenzhou Medical University First Affiliated Hospital

Junjie Chen

Wenzhou Medical University First Affiliated Hospital

Chengshui Chen

Wenzhou Medical University First Affiliated Hospital

Ying Zhou

Wenzhou Medical University First Affiliated Hospital

Yuping Li ( $\nabla$ wzliyp@163.com )

Department of Pulmonary and Critical Care Medicine, The First Affiliated Hospital of Wenzhou Medical University https://orcid.org/0000-0002-5833-931X

Research article

Keywords: Pneumonia, Psittacosis, Chlamydia psittaci, Legionella, Next-generation sequencing

Posted Date: July 24th, 2020

DOl: https://doi.org/10.21203/rs.3.rs-45675/v1

License: (1) This work is licensed under a Creative Commons Attribution 4.0 International License.

Read Full License 


\section{Abstract \\ Background}

Legionella and Chlamydia psittaci cause atypical community-acquired pneumonia, which mimic each other. Our aim was to compare the clinical characteristics of Legionella pneumonia (LP) and psittacosis and assess whether metagenomic next-generation sequencing (mNGS) is an effective method for early diagnosis.

\section{Methods}

We conducted a retrospective study and compared seventeen patients with Chlamydia psittaci pneumonia and nine patients with LP, diagnosed by mNGS. This study was carried out in the First Affiliated Hospital of Wenzhou Medical University, China, from July 2018 to May 2020. mNGS was carried out from bronchial alveolar lavage fluid (BALF) and/or lung tissues.

\section{Results}

$76.5 \%$ of psittacosis cases and $0 \%$ of legionellosis cases had an avian exposure history $(p<0.001)$. Compared with LP patients, psittacosis patients had significantly higher hemoglobin (118.9 $\pm 20.2 \mathrm{vs.}$ $93.2 \pm 23.2 \mathrm{~g} / \mathrm{L}, p=0.007$ ), serum sodium ( $138.9 \pm 5.4 \mathrm{vs} .133 .9 \pm 6.5 \mathrm{mmol} / \mathrm{L}, p=0.047$ ), and higher proportion of elevated aspartate aminotransferase levels ( 88.2 vs. $44.4 \%, p=0.028)$. Other clinical parameters were similar in psittacosis and LP patients: normal or slightly elevated leucocytes (10.5 vs. $\left.9.5 \times 10^{9} / \mathrm{L}, p>0.05\right)$, neutrophils ( $\left.9.4 \mathrm{vs} .8 .3 \times 10^{9} / \mathrm{L}, p>0.05\right)$, and procalcitonin ( $0.8 \mathrm{vs} 5.1 \mathrm{ng} / \mathrm{mL}, p>$ 0.05 ); highly increased C-reactive protein levels (205.1 vs. $234.9 \mathrm{mg} / \mathrm{L}, p>0.05$ ); and decreased lymphocytes ( 0.7 vs. $\left.0.6 \times 10^{9} / \mathrm{L}, p>0.05\right)$. Extra-pulmonary manifestations and mortality $(11.8 \%$ in psittacosis vs. $22.2 \%$ in LP group, $p=0.591$ ) were also similar in both the groups. mNGS detected Chlamydia psittaci in 17/17 BALF samples, and Legionella in 8/8 BALF samples and 1/1 lung tissue sample.

\section{Conclusions}

Apart from sharing many features with legionellosis, psittacosis is a vital differential diagnosis for LP, especially in patients with avian exposure history. mNGS is a sensitive and promising method for early diagnosis of both psittacosis and LP.

\section{Background}


Community-acquired pneumonia (CAP) is associated with high morbidity and mortality worldwide[1]. Atypical pathogens such as Legionella, Mycoplasma pneumoniae, Chlamydia pneumoniae, and Chlamydia psittaci are the common causes (15-28\%) of CAP[2].

Chlamydia psittaci is an obligatory, intra-cellular gram-negative bacterium that may infect humans and cause zoonotic infection named psittacosis or parrot fever[3]. Usually, transmission occurs through inhalation of contaminated aerosols originating from the excretions of infected birds. Psittacosis can be asymptomatic or acute symptomatic infection characterized by mild influenza-like illness to severe pneumonia and extra-pulmonary systemic disease, which can be fatal. Chlamydia psittacileads to CAP in rare cases $(1.03 \%$, range: $0-6.7 \%)$ [4]. Because of the low disease awareness, nonspecific clinical manifestations, and lack of rapid and accurate diagnostic methods, psittacosis is easy to be underdiagnosed. Metagenomic next generation sequencing (mNGS) has been increasingly applied to diagnose many infectious diseases especially when traditional diagnostic methods have limitations[5]. With the widespread application of mNGS in clinical settings, psittacosis cases are getting reported frequently in recent years[6-8].

Legionella spp. are gram-negative intracellular bacteria that frequently leads to severe CAP (SCAP) requiring admission in intensive care unit (ICU). Legionella pneumonia (LP) is most likely caused by Legionella pneumophila. The most common bacterial mimics of legionnaire's disease (LD) are Streptococcus pneumoniae and psittacosis[9]. Studies have been conducted to determine whether LP can be distinguished from pneumonia caused by S. pneumoniae[10]. However, few studies describe the problem of differentiating LP from $C$. psittaci pneumonia in clinical settings.

We performed a retrospective study of 17 cases of $C$. psittaci pneumonia diagnosed by mNGS and compared them with 9 cases of LP. This comparison was carried out to find whether the cases differ in clinical manifestations and to demonstrate whether mNGS is an effective diagnostic method. We present the following article in accordance with the STROBE reporting checklist.

\section{Methods}

\section{Study design}

This was a retrospective study. The study was conducted in accordance with the Declaration of Helsinki. The study was approved by the Ethics Committee of the First Affiliated Hospital of Wenzhou Medical University. The requirement for informed consent was waived due to the retrospective nature of the study.

\section{Diagnostic criteria}

Cases of $C$. psittaci pneumonia met the following three criteria: (1) Fulfilled the diagnostic criteria for CAP[11]; (2) A specific DNA fragment of $C$. psittaci identified by mNGS; and (3) Negative routine etiological tests, including blood, sputum, and bronchial alveolar lavage fluid (BALF) culture. 
Cases of LP fulfilled the criteria for CAP and met at least one of the following criteria: (1) Legionella successfully isolated from a respiratory sample or lung tissue sample and cultured on buffered charcoal yeast extract (BCYE) media; (2) Positive urine test for Legionella antigen; (3) A specific DNA fragment of Legionella identified by mNGS and negative routine etiological tests.

\section{Study participants}

A total of seventeen cases with $C$. psittaci pneumonia and nine cases with LP who were admitted to the First Affiliated Hospital of Wenzhou Medical University, a tertiary hospital in Zhejiang, China, between July 2018 and May 2020. For each case, we extracted the demographic data, comorbidities, illness severity, clinical manifestations, laboratory and imaging data, treatment, and outcomes from electronic medical records.

\section{mNGS}

The procedures such as sample processing, DNA extraction, construction of DNA libraries, sequencing, and bioinformatic analysis were completed by BGI-Huada Genomics Institute (Shenzhen, China), according to the previously described procedures by Miao et al.[12].

\section{Statistical analysis}

Continuous variables were expressed as means \pm standard deviation (SD), or medians (25th, 75th percentiles), depending on whether the variables were normally distributed or not. Categorical variables were expressed as percentages. T-test or the Mann-Whitney U-test were used to compare continuous variables. Categorical variables were compared using chi-square or Fisher's exact test. A $p$ value of less than 0.05 was considered as statistically significant. All analyses were performed using the SPSS software (version 26.0, SPSS Inc., Chicago, Illinois).

\section{Results}

\section{Psittacosis and LP diagnosis}

During the study period, 17 patients were diagnosed with psittacosis, and 9 patients with LP. C. psittaci was detected in BALF samples of 17 psittacosis patients by mNGS. Blood and BALF cultures were negative for all the 17 patients. We detected Legionella pneumophila in BALF samples of 8 LP patients using mNGS and Legionella bozemanii in lung tissue sample through percutaneous lung biopsy of 1 patient using mNGS. Blood and BALF cultures were conducted for all LP patients; BALF samples of 3 out of 8 patients were found positive for Legionella pneumophila. Tissue culture conducted in 1 patient through percutaneous lung biopsy revealed Legionella bozemanii growth. The mean time when the culture turned positive was 9.5 days. Urine Legionella antigen test were found positive in 3 out of 9 patients.

\section{General characteristics}


The demographic and general characteristics of the patients are shown in Table 1.13 of the 17 patients of psittacosis group (76.5\%) and no patient of the LP group ( $0 \%$ ) had a history of avian or poultry exposure $(p<001)$. The median time from onset of illness to admission was 5 days in both the groups. Psittacosis patients were admitted at all seasons while no LP patients were admitted in the winter. $41.2 \%$ of the psittacosis patients (7/17) were admitted in the spring, while $44.4 \%$ of the LP patients (4/9) were admitted in the autumn.

\section{Clinical characteristics}

All the patients infected with psittacosis and LP were febrile with a mean temperature of $39.8^{\circ} \mathrm{C}$. Majority of the patients in both the groups had similar symptoms (no significant difference): non-specific rigors, fatigue, cough, sputum, and dyspnoea. Also, many extra-pulmonary manifestations were similar between both the two groups: relative bradycardia, neurological symptoms (such as headache, dizziness), and gastrointestinal symptoms (vomiting and diarrhea). Meanwhile, 5 patients in the psittacosis group and 1 in the LP group were complicated with rhabdomyolysis. The diagnosis of rhabdomyolysis was confirmed when the level of serum creatine kinase (CK) was found higher than $1000 \mathrm{U} / \mathrm{L}[13]$. Clinical manifestations of the patients are shown in Table 2.

The laboratory and radiological tests results are shown in Table 3. The psittacosis patients had a mean white blood cell counts, neutrophils and lymphocyte of $10.5 \times 10^{9} / \mathrm{L}, 9.4 \times 10^{9} / \mathrm{L}$, and $0.7 \times 10^{9} / \mathrm{L}$, respectively, while the corresponding counts in LP patients were $9.5 \times 10^{9} / \mathrm{L}, 8.3 \times 10^{9} / \mathrm{L}$, and $0.6 \times 10^{9} / \mathrm{L}$ respectively. Similarly, C-reactive protein (CRP) and procalcitonin (PCT) levels were $205.1 \mathrm{mg} / \mathrm{L}$ and $0.8 \mathrm{ng} / \mathrm{mL}$, respectively, in psittacosis patients whereas the corresponding levels in the LP patients were $234.9 \mathrm{mg} / \mathrm{L}$ and $5.1 \mathrm{ng} / \mathrm{mL}$. As compared with LP patients, psittacosis patients had significantly higher levels of hemoglobin, serum sodium, and higher proportion of elevated aspartate aminotransferase (AST). Both the groups had elevated levels of IL-6. Moreover, consolidation, inflammatory exudation, and pleural effusions were frequently observed in computed tomography (CT) scans in both psittacosis and LP patients (Fig. 1, 2).

\section{Treatment and outcomes}

All antimicrobial treatments received by the patients are listed in Table $4.23 .5 \%$ of psittacosis and $44.4 \%$ of LP patients did not receive active antibiotics against $C$. psittaci or Legionella on admission. Reporting of the mNGS results took $48-72 \mathrm{~h}$ from the time of receipt of the samples. One psittacosis patient refused hemodialysis and one LP patient refused invasive mechanical ventilation; both the patients received carbapenem as initial empirical antibiotic and died before receiving their mNGS reports. Quinolone (moxifloxacin, $0.4 \mathrm{~g}$ intravenously q.d.) was frequently administered to patients of both the groups. The median fever clearance time in psittacosis patients (6 days) did not significantly differ from that in LP patients (5 days). 58.8\% (10/17) of psittacosis and $44.4 \%$ (4/9) of LP patients fulfilled the criteria for SCAP. The final prognosis was similar in both the groups; hospital mortality rate was $11.8 \%$ $(2 / 17)$ in psittacosis patients and $22.2 \%(2 / 9)$ in LP patients $(p=0.591)$. 


\section{Discussion}

Legionella accounts for approximately 1 to $10 \%$ of CAP and is the second most common cause of SCAP, which requires ICU admission[14]. Although $C$. psittaci is documented as an uncommon cause of CAP, CAP cases induced by $C$. psittaci may be underdiagnosed. A French study on distinctive features of pneumonia caused by $C$. psittaci and L. pneumophila showed that severe psittacosis and severe legionellosis share many common characteristics in ICU patients[15]. However, the recommended first line antibiotics are different for psittacosis and LP. For Legionella species, fluoroquinolone and azithromycin are the preferred antimicrobials, while for $C$. psittaci tetracycline is recommended[11, 16]. Consequently, to an optimal initial administration of empirical antibiotics, the differentiation of psittacosis from LP is frequently concerned in clinical practice.

Our results suggest that psittacosis and LP indeed share many similarities consistent with reported findings $[6,15,17]$. They both manifest as hyperpyrexia with a mean temperature of $39.8^{\circ} \mathrm{C}$. In addition, they have similar extra-pulmonary symptoms: neurological symptoms, gastrointestinal symptoms, relative bradycardia and rhabdomyolysis. Legionella-associated rhabdomyolysis has been frequently reported in literature[18, 19]. Rhabdomyolysis is not usually caused by pathogens, but most pathogeninduced rhabdomyolysis in the patients is due to an infection by Legionella species[18]. The exact mechanism is unclear, but it involves either the release of endotoxin in the circulation, resulting in muscle and kidney damage, or the direct invasion of Legionella into the muscle tissues[20]. Meanwhile, case reports suggest that rhabdomyolysis also occurs in psittacosis[21, 22]. Our study reveals that psittacosisassociated rhabdomyolysis is not rare, and even more common than Legionella (no significant difference). But the mechanism behind the complication of psittacosis by rhabdomyolysis is unknown. The laboratory findings of psittacosis and LP groups generally showed normal or slightly increased white blood cell counts, neutrophils, and PCT level, highly elevated CRP, and decreased lymphocytes. Gacouin et al. reported that the outcome of patients with psittacosis is similar to that of LP patients[15]. Our study also reveals that psittacosis and LP groups share similar proportion of SCAP and outcomes.

However, there are some differences between psittacosis and LP. We observed that $76.5 \%$ of the patients with psittacosis and $0 \%$ of the patients with LP had a contact with birds. Studies report that about $70 \%$ of psittacosis cases have a known source of infection as a result of contact with birds[23]. A study reported that $100 \%$ of the psittacosis cases had a bird exposure history while the corresponding percentage for LP cases is only $5.9 \%[15]$. Therefore, a history of avian or poultry contact is an important diagnostic feature of psittacosis.

This study also shows that psittacosis patients are admitted at all seasons, and LP patients are not admitted in the winter season. Moreover, $41.2 \%$ of the psittacosis patients were admitted in the spring, while $44.4 \%$ of the LP patients were admitted in the autumn. In a Britain study, no seasonal variation was observed in psittacosis[24]. Furthermore, a higher portion of pigeons were found positive for $C$. psittaci IgG antibodies in the spring season. This observation suggests that pigeons may act as a significant source of human infection during the spring season [25]. Furthermore, raising poultry in all the seasons is 
quite common in China, which adds to the problem. Legionnaires' disease is more common in the late summer and early autumn, seasons that are associated with wet and humid weather[26]. In our study, $44.4 \%$ of LP patients were admitted in the autumn and $0 \%$ in the winter season. This trend might be due to the fact that the weather in Wenzhou, China is wet throughout the year except winters. However, due to a limited sample size, the correlation between the admission of psittacosis or LP patients and the seasons could not be elucidated.

In Legionella CAP and psittacosis, hepatic involvement is common and generally manifested by mildly increased serum transaminases $[9,23]$. It is reported that abnormal liver function tests occurs in some cases of psittacosis, and occurs in many cases in LP[17]. However, in our study, a significant number of patients with psittacosis had a higher proportion of elevated AST. We hypothesize that this observation might be attributed to the co-involvement of rhabdomyolysis. In addition, compared to psittacosis patients, LP patients have lower levels of serum sodium and hemoglobin. LP is frequently associated with hyponatremia[23], which may in turn be associated with the syndrome of inappropriate antidiuretic hormone secretion[27]. There is some anecdotal evidence associating hemolytic anemia to legionellosis, but the underlying mechanism is unknown[28, 29]. However, in our study, the bilirubin levels in both LP and psittacosis patients were found to be in the normal range, suggesting no evidence of hemolytic anemia. 2 LP patients out of 9 had comorbidities of chronic renal failure; another 2 patients had hematologic diseases (1 patient had myeloproliferative neoplastic disease and the other one had leukemia) (no significant difference as compared with psittacosis, data not shown). The comorbidities may be the cause of the lower hemoglobin levels in LP patients. As compared with severe legionellosis patients, patients with severe psittacosis are reported to be younger and less frequent smokers, having fewer chronic diseases and longer duration of pre-hospital symptoms[15]. However, in our study both legionellosis and psittacosis patients shared similar such features. The differences between our study and the reported studies might be due to variations in study population.

Although certain clinical features may suggest Legionella or $C$. psittaci infection, microbiological tests are required to confirm the diagnosis. Available diagnostic methods for $C$. psittaci infection are not ideal. Culture methods are time consuming and requires at least biosafety level III facility[30]. Serological tests are suitable for retrospective diagnosis as sera are required in both acute and convalescent phases[31]. Also, cross-reactivity with other Chlamydia spp. also poses problems[3]. Polymerase chain reaction (PCR) based testing is a more specific and rapid detecting method but has high sensitivity only in the acute stage[32]. For diagnosis of legionnaire's disease, in vitro culture is the gold standard, requiring a specific $B C Y E$ agar media. However, the prolonged incubation time of $\geq 3$ days limits its utility for early diagnosis[3]. Also, prior antibiotic exposure in the patient may decrease the culture positivity. The urinary antigen test, of good sensitivity and specificity[33], can detect the pathogen early and the antigen persists for several weeks despite the antibacterial therapy[3]. But such tests can only detect $L$. pneumophila serogroup I. PCR assays can rapidly detect most Legionella species, but its sensitivity and specificity varies[34, 35]. Moreover, PCR is available only in a few hospitals in China. 
mNGS has emerged as a high-throughput method for pathogen identification and is superior to the currently available microbiological diagnostic methods for the identification of hard-to-culture pathogens. Because of its potential to use non-specific primers and a short turnaround time, mNGS can detect etiologic pathogens rapidly, leading to early diagnosis and a better prognosis[36]. Furthermore, mNGS is less affected by prior antibiotic exposure[12]. Several studies have discussed the potential of mNGS in diagnosing psittacosis or legionnaire's disease[6-8,37]. In our study, all 17 psittacosis patients and 9 LP patients were diagnosed with the help of mNGS. Only $44.4 \%$ (4/9) patients tested positive for Legionella using culture methods, with a mean time to positivity as 9.5 days. Urine Legionella antigen test was positive only in $33.3 \%$ (3/9) patients. Therefore, mNGS may be a promising and rapid method for diagnosing psittacosis or legionnaire's disease.

The tetracyclines are the preferred antibiotics for the treatment of psittacosis[11, 16]. Macrolides are considered as alternatives for patients who are contraindicated for tetracyclines[16]. Studies are needed to establish the utility of quinolones in treating these diseases. A few fluoroquinolones were found to be active against $C$. psittaci in experimental models[17]. In the present study, quinolones were administered to 10 psittacosis patients, and on one out of 10 died, indicating that quinolones may be effective against C. psittaci. The unavailability of doxycycline in the hospital might be a reason why quinolones were frequently administered in our study. Besides, the use of tigecycline is restricted because of the high price and high incidence of hepatic side effects.

This study has several limitations. Sample size of this study is limited, and the diagnosis of psittacosis was made solely through mNGS, with no confirmation by other methods. However, clinical manifestations are consistent with literature and BALF in all cases showed $C$. psittaci reads with mNGS. Further, direct comparison between psittacosis and LP provides important information on the differential diagnosis of the two diseases based on clinical parameters.

\section{Conclusions}

There are many similarities between psittacosis and LP, including extra-pulmonary manifestations, biological features, and prognosis. Psittacosis is a vital differential diagnosis of LP, especially in patients with prior avian exposure. mNGS is a sensitive tool and has potential for the early detection of $C$. psittaci and Legionella. These preliminary findings should be correlated with diagnostic trials in the future studies.

\section{Abbreviations}

ALT: Alanine aminotransferase; AST: Aspartate aminotransferase; BALF: Bronchial alveolar lavage fluid; BCYE: Buffered charcoal yeast extract; BNP: B natriuretic peptide; CAP: Community-acquired pneumonia; CK: Creatine kinase; CRP: C-reactive protein; CT: Computed tomography; ICU: Intensive care unit; LD: Legionnaire's disease; LDH: Lactate dehydrogenase; LP: Legionella pneumonia; mNGS: Metagenomic 
next generation sequencing; PCR: Polymerase chain reaction; PCT: Procalcitonin; SCAP: Severe CAP; SD: Standard deviation; WBC: White blood cell

\section{Declarations}

\section{Acknowledgments}

Not Applicable.

\section{Authors' contributions}

YZ and YPL participated in study conception and design. SSS, JHZ, YLL and PCL collected and assembled the data. JJC and CSC participated in data analysis and interpretation. All authors read and approved the final manuscript.

\section{Funding}

This work was supported by the Project of National Natural Science Foundation of China [Grant number 81970066]. The funding body had no role in the study design, the collection, analysis or interpretation of the data.

\section{Availability of data and materials}

The dataset used and/or analyzed during the current study are available from the corresponding author on reasonable request.

\section{Ethics approval and consent to participate}

The study was approved by the Ethics Committee of the First Affiliated Hospital of Wenzhou Medical University. The requirement for informed consent was waived due to the retrospective nature of the study. The study was conducted in accordance with the Declaration of Helsinki.

\section{Consent for publication}

Not Applicable.

\section{Competing interests}

The authors have no conflicts of interest to declare.

\section{Author details}

${ }^{1}$ Department of Pulmonary and Critical Care Medicine, The First Affiliated Hospital of Wenzhou Medical University, Wenzhou, China. ${ }^{2}$ Department of Pulmonary and Critical Care Medicine, Yueqing City People's Hospital, Yueqing, China. 


\section{References}

1. File TM, Marrie TJ. Burden of Community-Acquired Pneumonia in North American Adults. Postgrad Med. 2010;122(2):130-41.

2. Arnold FW, Summersgill JT, Lajoie AS, Peyrani P, Marrie TJ, Rossi P, Blasi F, Fernandez P, File TM, Rello J, et al. A worldwide perspective of atypical pathogens in community-acquired pneumonia. Am J Resp Crit Care. 2007;175(10):1086-93.

3. Lamoth F, Greub G. Fastidious intracellular bacteria as causal agents of community-acquired pneumonia. Expert Rev Anti-Infe. 2010;8(7):775-90.

4. Hogerwerf L, De Gier B, Baan B, Van Der Hoek W. Chlamydia psittaci (psittacosis) as a cause of community-acquired pneumonia: a systematic review and meta-analysis. Epidemiol Infect. 2017;145(15):3096-105.

5. Gu W, Miller S, Chiu CY. Clinical Metagenomic Next-Generation Sequencing for Pathogen Detection. Annu Rev Pathol. 2019;14:14:319-38.

6. Chen X, Cao K, Wei Y, Qian Y, Liang J, Dong D, Tang J, Zhu Z, Gu Q, Yu W: Metagenomic nextgeneration sequencing in the diagnosis of severe pneumonias caused by Chlamydia psittaci. Infection 2020.

7. Zhang H, Zhan D, Chen D, Huang W, Yu M, Li Q, Marcos PJ, Tattevin P, Wu D, Wang L. Next-generation sequencing diagnosis of severe pneumonia from fulminant psittacosis with multiple organ failure: a case report and literature review. Annals of Translational Medicine. 2020;8(6):401-1.

8. Gu L, Liu W, Ru M, Lin J, Yu GQ, Ye J, Zhu ZA, Liu YB, Chen J, Lai GX, et al: The application of metagenomic next-generation sequencing in diagnosing Chlamydia psittaci pneumonia: a report of five cases. Bmc Pulm Med 2020, 20(1).

9. Cunha BA, Cunha CB. Legionnaire's Disease and its Mimics: A Clinical Perspective. Infect Dis Clin N Am. 2017;31(1):95-+.

10. Sopena N, Sabrià-Leal M, Pedro-Botet ML, Padilla E, Dominguez J, Morera J, Tudela P. Comparative study of the clinical presentation of Legionella pneumonia and other community-acquired pneumonias. Chest. 1998;113(5):1195-200.

11. Mandell LA, Wunderink RG, Anzueto A, Bartlett JG, Campbell GD, Dean NC, Dowell SF, File TM, Musher DM, Niederman MS, et al. Infectious Diseases Society of America/American Thoracic Society consensus guidelines on the management of community-acquired pneumonia in adults. Clin Infect Dis. 2007;44:27-72.

12. Miao Q, Ma Y, Wang Q, Pan J, Zhang Y, Jin W, Yao Y, Su Y, Huang Y, Wang M, et al. Microbiological Diagnostic Performance of Metagenomic Next-generation Sequencing When Applied to Clinical Practice. Clin Infect Dis. 2018;67(suppl_2):231-s240.

13. Cabral BMI, Edding SN, Portocarrero JP, Lerma EV. Rhabdomyolysis. Dis Mon 2020:101015.

14. von Baum H, Ewig S, Marre R, Suttorp N, Gonschior S, Welte T, Luck C, Acq CNC. Community-acquired Legionella pneumonia: new insights from the German Competence Network for Community Acquired 
Pneumonia. Clin Infect Dis. 2008;46(9):1356-64.

15. Gacouin A, Revest M, Letheulle J, Fillatre P, Jouneau S, Piau C, Uhel F, Tattevin P, Le Tulzo Y. Distinctive features between community-acquired pneumonia (CAP) due to Chlamydophila psittaci and CAP due to Legionella pneumophila admitted to the intensive care unit (ICU). Eur J Clin Microbiol. 2012;31(10):2713-8.

16. Balsamo G, Maxted AM, Midla JW, Murphy JM, Wohrle R, Edling TM, Fish PH, Flammer K, Hyde D, Kutty PK, et al. Compendium of Measures to ControlChlamydia psittacilnfection Among Humans (Psittacosis) and Pet Birds (Avian Chlamydiosis), 2017. J Avian Med Surg. 2017;31(3):262-82.

17. Stewardson AJ, Grayson ML. Psittacosis. Infect Dis Clin North Am. 2010;24(1):7-25.

18. Soni AJ, Peter A. Established association of legionella with rhabdomyolysis and renal failure: A review of the literature. Respir Med Case Rep. 2019;28:100962.

19. Buzzard JW, Zuzek Z, Alencherry BP, Packer CD. Evaluation and Treatment of Severe Rhabdomyolysis in a Patient with Legionnaires' Disease. Cureus. 2019;11(9):e5773.

20. McConkey J, Obeius M, Valentini J, Beeson MS. Legionella pneumonia presenting with rhabdomyolysis and acute renal failure: A case report. J Emerg Med. 2006;30(4):389-92.

21. Matsushima H, Takayanagi N, Ubukata M, Tokunaga D, Mori S, Sato N, Kurashima K, Yanagisawa T, Sugita Y, Kanazawa M. [A case of fulminant psittacosis with rhabdomyolysis]. Nihon Kokyuki Gakkai Zasshi. 2002;40(7):612-6.

22. Kawamura S, Ikematsu H, Ogimoto $\mathrm{H}$. [Two cases of psittacosis accompanied with rhabdomyolysis]. Kansenshogaku Zasshi. 1990;64(9):1239-43.

23. Cillóniz C, Torres A, Niederman M, van der Eerden M, Chalmers J, Welte T, Blasi F. Communityacquired pneumonia related to intracellular pathogens. Intens Care Med. 2016;42(9):1374-86.

24. Nagington J. Psittacosis/ornithosis in Cambridgeshire 1975-1983. J Hyg (Lond). 1984;92(1):9-19.

25. Travnicek M, Cislakova L, Deptula W, Stosik M, Bhide MR. Wild pigeons and pheasants - A source of Chlamydophila psittaci for humans and animals. Ann Agr Env Med. 2002;9(2):253-5.

26. Cassell K, Gacek P, Warren JL, Raymond PA, Cartter M, Weinberger DM. Eight Years of Clinical Legionella PCR Testing Illustrates a Seasonal Pattern Reply. J Infect Dis. 2018;218(4):670-1.

27. Shepshelovich D, Leibovitch C, Klein A, Zoldan S, Milo G, Shochat T, Rozen-zvi B, Gafter-Gvili A, Lahav $M$. The syndrome of inappropriate antidiuretic hormone secretion: Distribution and characterization according to etiologies. Eur J Intern Med. 2015;26(10):819-24.

28. Durrance RJ, Das Gracas F, Sivamurthy S, Singh BB. Legionella-Induced Autoimmune Hemolytic Anemia: A Delayed and Unexpected Complication. J Hematol. 2019;8(1):44-5.

29. Strikas R, Seifert MR, Lentino JR. Autoimmune hemolytic anemia and Legionella pneumophila pneumonia. Ann Intern Med. 1983;99(3):345.

30. Rybarczyk J, Versteele C, Lernout T, Vanrompay D. Human psittacosis: a review with emphasis on surveillance in Belgium. Acta Clin Belg. 2019;75(1):42-8. 
31. Tuuminen T, Palomaki P, Paavonen J. The use of serologic tests for the diagnosis of chlamydial infections. J Microbiol Meth. 2000;42(3):265-79.

32. Nieuwenhuizen AA, Dijkstra F, Notermans DW, van der Hoek W. Laboratory methods for case finding in human psittacosis outbreaks: a systematic review. Bmc Infect Dis 2018, 18.

33. Shimada T, Noguchi Y, Jackson JL, Miyashita J, Hayashino Y, Kamiya T, Yamazaki S, Matsumura T, Fukuhara S. Systematic Review and Metaanalysis Urinary Antigen Tests for Legionellosis. Chest. 2009;136(6):1576-85.

34. Tronel H, Hartemann P. Overview of diagnostic and detection methods for legionellosis and Legionella spp. Lett Appl Microbiol. 2009;48(6):653-6.

35. Murdoch DR. Diagnosis of Legionella infection. Clin Infect Dis. 2003;36(1):64-9.

36. Naccache SN, Federman S, Veeraraghavan N, Zaharia M, Lee D, Samayoa E, Bouquet J, Greninger AL, Luk KC, Enge B, et al. A cloud-compatible bioinformatics pipeline for ultrarapid pathogen identification from next-generation sequencing of clinical samples. Genome Res. 2014;24(7):118092.

37. Yi HH, Fang J, Huang JW, Liu B, Qu JM, Zhou M. Legionella pneumophila as Cause of Severe Community-Acquired Pneumonia, China. Emerg Infect Dis. 2020;26(1):160-2.

\section{Tables}

Table.1 General characteristics of patients with psittacosis versus Legionella pneumonia 


\begin{tabular}{|c|c|c|c|}
\hline Characteristics & $\begin{array}{l}\text { C. psittaci } \\
\text { pneumonia }(\mathrm{n}=17)\end{array}$ & $\begin{array}{l}\text { Legionella } \\
\text { pneumonia }(\mathrm{n}=9)\end{array}$ & $p$-value \\
\hline Ages, years & $62.1 \pm 9.7$ & $56.6 \pm 20.8$ & 0.465 \\
\hline Male, n(\%) & $9(52.9)$ & $7(77.8)$ & 0.399 \\
\hline $\begin{array}{l}\text { Current smoker, Current drinker, } \\
\text { n (\%) }\end{array}$ & $5(29.4)$ & $3(33.3)$ & 1.000 \\
\hline $\begin{array}{l}\text { History of contact with avian or } \\
\text { poultry, n (\%) }\end{array}$ & $13(76.5)$ & $0(0)$ & $<0.001$ \\
\hline $\begin{array}{l}\text { Chronic underlying diseases, } \mathrm{n} \\
\text { (\%) }\end{array}$ & $10(58.8)$ & $8(88.9)$ & 0.190 \\
\hline $\begin{array}{l}\text { Symptoms duration before } \\
\text { admission, days }\end{array}$ & $5.0(3.0,7.5)$ & $5.0(3.0,7.0)$ & 0.634 \\
\hline Season of admission, $\mathrm{n}(\%)$ & & & 0.910 \\
\hline Spring & $7(41.2)$ & $3(33.3)$ & \\
\hline Summer & $4(23.5)$ & $2(22.2)$ & \\
\hline Autumn & $3(17.6)$ & $4(44.4)$ & \\
\hline Winter & $3(17.6)$ & $0(0)$ & \\
\hline
\end{tabular}

Table.2 Clinical manifestations of patients with psittacosis versus Legionella pneumonia 


\begin{tabular}{llll}
\hline Characteristics & $\begin{array}{l}\text { C. psittaci pneumonia } \\
(\mathrm{n}=17)\end{array}$ & $\begin{array}{l}\text { Legionella pneumonia } \\
(\mathrm{n}=9)\end{array}$ & $\begin{array}{c}p \text { - } \\
\text { value }\end{array}$ \\
\hline Fever, n(\%) & $17(100)$ & $9(100)$ & - \\
Temperature & $39.8 \pm 0.5$ & $39.8 \pm 0.3$ & 0.974 \\
\hline Rigors, $\mathrm{n}(\%)$ & $12(70.6)$ & $3(33.3)$ & 0.103 \\
\hline Fatigue, $\mathrm{n}(\%)$ & $8(47.1)$ & $6(66.7)$ & 0.429 \\
\hline Myalgia, $\mathrm{n}(\%)$ & $4(23.5)$ & $0(0)$ & 0.263 \\
\hline Cough, n(\%) & $14(82.4)$ & $8(88.9)$ & 1.000 \\
\hline Sputum, $\mathrm{n}(\%)$ & $12(70.6)$ & $6(66.7)$ & 1.000 \\
\hline Dyspnoea, n(\%) & $13(76.5)$ & $7(77.8)$ & 1.000 \\
\hline Extrapulmonary findings, & $\mathrm{n}(\%)$ & $5(55.6)$ & 0.692 \\
\hline Relative bradycardia & $11(64.7)$ & $1(11.1)$ & 0.098 \\
\hline Neurological symptoms & $8(47.1)$ & $1(11.1)$ & 1.000 \\
\hline Gastrointestinal & $3(17.6)$ & & 0.380 \\
\hline symptoms & & $1(11.1)$ & \\
\hline Rhabdomyolysis & $5(29.4)$ & & \\
\hline
\end{tabular}

Table.3 Laboratory and radiological findings of patients with psittacosis versus Legionella pneumonia 


\begin{tabular}{|c|c|c|c|}
\hline Characteristics & $\begin{array}{l}\text { C. psittaci pneumonia } \\
(\mathrm{n}=17)\end{array}$ & $\begin{array}{l}\text { Legionella pneumonia } \\
(\mathrm{n}=9)\end{array}$ & $\begin{array}{l}p \text { - } \\
\text { value }\end{array}$ \\
\hline WBC, $\times 10 \square / L$ & $10.5 \pm 6.3$ & $9.5 \pm 5.3$ & 0.672 \\
\hline Elevated WBC & $8(47.1)$ & $3(33.3)$ & 0.683 \\
\hline Neutrophils, $\times 10 \square / L$ & $9.4 \pm 5.9$ & $8.3 \pm 5.4$ & 0.647 \\
\hline Lymphocyte, $\times 10 \square / L$ & $0.7 \pm 0.4$ & $0.6 \pm 0.2$ & 0.390 \\
\hline Decreased lymphocyte & $16(94.1)$ & $9(100)$ & 1.000 \\
\hline Hemoglobin, g/L & $118.9 \pm 20.2$ & $93.2 \pm 23.2$ & 0.007 \\
\hline $\mathrm{CRP}, \mathrm{mg} / \mathrm{L}$ & $205.1 \pm 90.0$ & $234.9 \pm 114.0$ & 0.471 \\
\hline $\mathrm{PCT}, \mathrm{ng} / \mathrm{mL}$ & $0.8(0.3,6.0)$ & $5.1(1.2,27.9)$ & 0.063 \\
\hline $\mathrm{ALT}, \mathrm{U} / \mathrm{L}$ & $78.0(37.0,125.5)$ & $24.0(10.5,101.5)$ & 0.112 \\
\hline AST, U/L & $140.0(48.0,271.5)$ & $31.0(20.0,170.5)$ & 0.071 \\
\hline Elevated AST & $15(88.2)$ & $4(44.4)$ & 0.028 \\
\hline Urea, mmol/L & $10.1 \pm 8.6$ & $11.2 \pm 7.6$ & 0.757 \\
\hline Creatinine, $\mu \mathrm{mol} / \mathrm{l}$ & $64.0(53.0,213.5)$ & $78.0(71.5,154.0)$ & 0.403 \\
\hline $\begin{array}{l}\text { Serum sodium, } \\
\mathrm{mmol} / \mathrm{L}\end{array}$ & $138.9 \pm 5.4$ & $133.9 \pm 6.5$ & 0.047 \\
\hline $\mathrm{LDH}, \mathrm{U} / \mathrm{L}$ & $481.5(359.3,725.5)$ & $430.0(316.3,597.8)$ & 0.327 \\
\hline $\mathrm{CK}, \mathrm{U} / \mathrm{L}$ & $456.0(91.5,2270.0)$ & $104.0(32.5,263.0)$ & 0.063 \\
\hline $\mathrm{BNP}, \mathrm{pg} / \mathrm{mL}$ & $185.0(54.0,256.0)$ & $377.0(84.0,624.0)$ & 0.456 \\
\hline CD4+ T cell & $305.8 \pm 185.8$ & $167.9 \pm 93.8$ & 0.082 \\
\hline CD8+ T cell & $99.0(70.3,129.0)$ & $112.0(78.0,161.0)$ & 0.601 \\
\hline IL-6, pg/mL & $307.3(89.4,1141.8)$ & $314.9(115.2,1908.1)$ & 0.934 \\
\hline IL-10, pg/mL & $8.3(4.2,20.2)$ & $6.5(3.2,64.3)$ & 0.934 \\
\hline IFN- $\gamma, \mathrm{pg} / \mathrm{mL}$ & $31.9(9.7,198.0)$ & $17.8(6.4,57.7)$ & 0.284 \\
\hline $\begin{array}{l}\mathrm{P}_{\mathrm{a}} \mathrm{O}_{2} / \mathrm{F}_{\mathrm{i}} \mathrm{O}_{2} \text { ratio, } \\
\mathrm{mmHg}\end{array}$ & $218.3 \pm 114.2$ & $244.2 \pm 78.4$ & 0.552 \\
\hline \multicolumn{4}{|l|}{ Imaging } \\
\hline Consolidation & $14(82.4)$ & $8(88.9)$ & 1.000 \\
\hline Inflammatory & $8(47.1)$ & $6(66.7)$ & 0.429 \\
\hline
\end{tabular}


exudation

Pleural effusions

$13(76.5)$

$6(66.7)$

0.661

WBC white blood cell, CRP C-reactive protein, PCT procalcitonin, ALT Alanine

aminotransferase, AST Aspartate aminotransferase, LDH lactate dehydrogenase, CK creatine kinase, BNP B natriuretic peptide

Table.4 Treatment and outcomes of patients with psittacosis versus Legionella pneumonia 


\begin{tabular}{|c|c|c|c|}
\hline & $\begin{array}{l}\text { C. psittaci pneumonia } \\
(\mathrm{n}=17)\end{array}$ & $\begin{array}{l}\text { Legionella pneumonia } \\
(\mathrm{n}=9)\end{array}$ & $\begin{array}{l}p \text { - } \\
\text { value }\end{array}$ \\
\hline $\begin{array}{l}\text { Empirical antibiotics not } \\
\text { covered }\end{array}$ & $4(23.5)$ & $4(44.4)$ & 0.382 \\
\hline Antimicrobial therapy & & & 0.305 \\
\hline Tetracycline & $1(6.3)^{\dagger}$ & $0(0)^{\ddagger}$ & \\
\hline Macrolides & $3(18.8)^{\dagger}$ & $0(0)^{\ddagger}$ & \\
\hline Quinolones & $10(62.5)^{\dagger}$ & $6(75.0)^{\ddagger}$ & \\
\hline $\begin{array}{l}\text { Combination of above } \\
\text { antibiotics }\end{array}$ & $2(12.5)^{\dagger}$ & $2(25.0)^{\ddagger}$ & \\
\hline Fever clearance time, days & $6.0(4.3,7.0)$ & $5.0(2.0,7.0)$ & 0.311 \\
\hline SCAP, n(\%) & $10(58.8)$ & $4(44.4)$ & 0.683 \\
\hline Respiratory support, n(\%) & & & 0.782 \\
\hline Invasive ventilation & $7(41.2)$ & $2(22.2)$ & \\
\hline Non-invasive ventilation & $0(0)$ & $2(22.2)$ & \\
\hline No mechanical ventilation & $10(58.8)$ & $5(55.6)$ & \\
\hline Septic shock, n(\%) & $11(64.7)$ & $4(44.4)$ & 0.419 \\
\hline Hemodialysis, n(\%) & $3(17.6)$ & $1(11.1)$ & 1.000 \\
\hline $\begin{array}{l}\text { Median length of hospital } \\
\text { stay, days }\end{array}$ & $12.0(10.0,16.5)$ & $13.0(8.0,30.0)$ & 0.865 \\
\hline Death, n(\%) & $2(11.8)$ & $2(22.2)$ & 0.591 \\
\hline
\end{tabular}

\section{Figures}




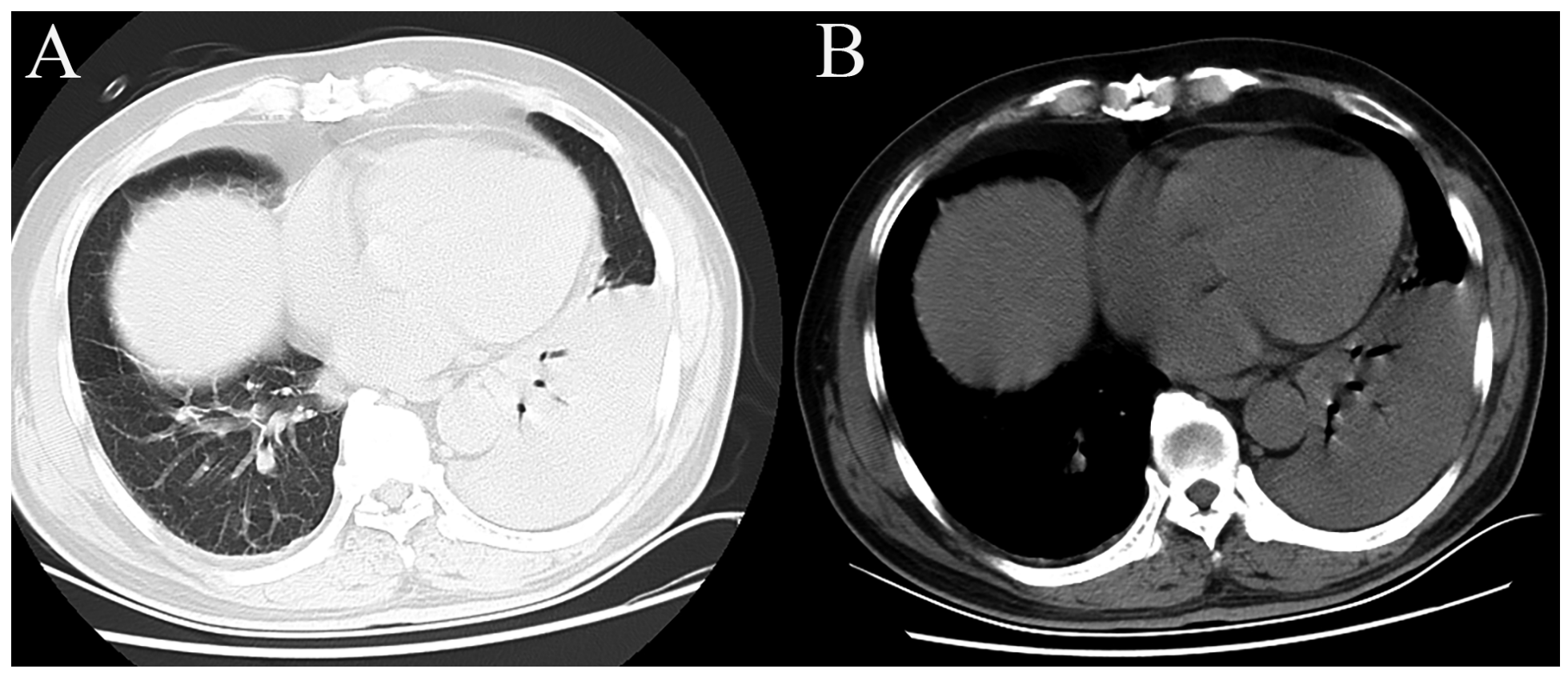

Figure 1

Chest computed tomography (CT) scan of a 71-year-old man with psittacosis on the day of admission (2 days after onset). It shows air-space consolidation in left lower lobe. A, lung window; B, mediastinum window.

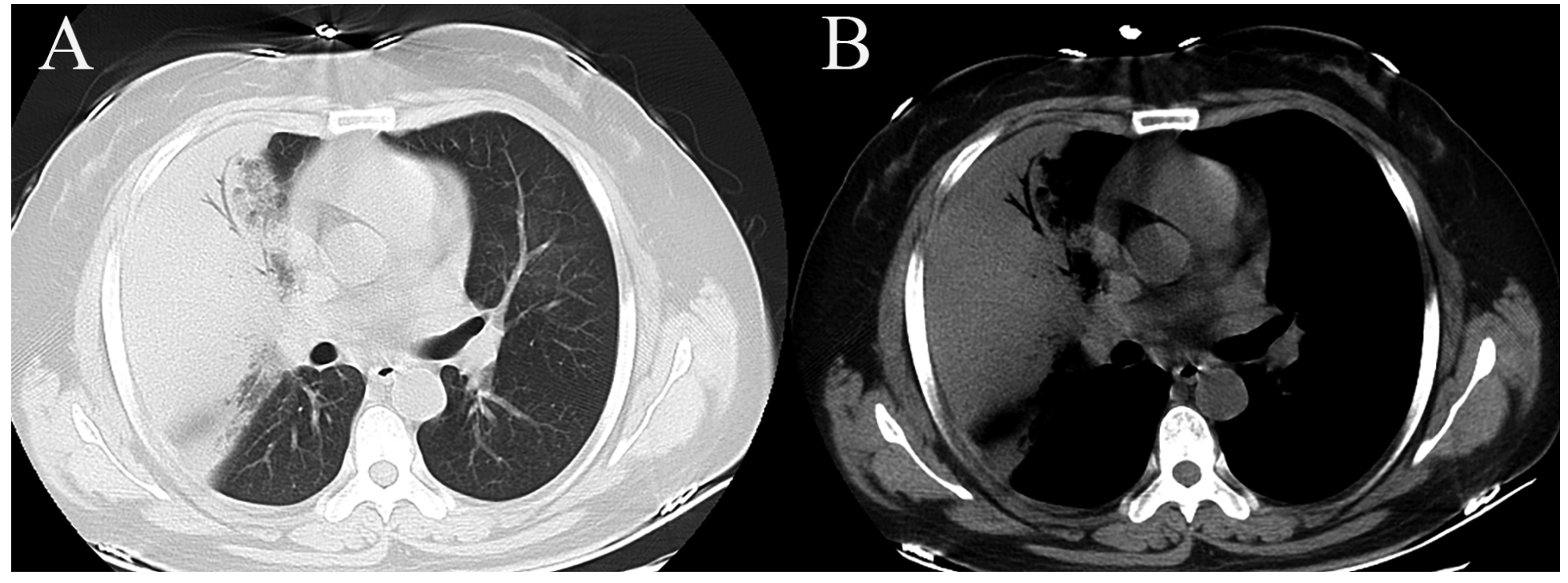

Figure 2

Chest computed tomography (CT) scan of a 45-year-old woman with Legionella pneumonia on the day of admission (3 days after onset). It shows air-space consolidation and inflammatory exudation in right middle lobe, with small interlobar effusion. A, lung window; B, mediastinum window. 